\title{
O teletrabalho durante a pandemia da covid- 19: indicadores da intensificação do trabalho docente
}

\author{
Teleworking during the covid-19 pandemic: \\ indicators of intensification of teaching work \\ Télétravail pendant la pandémie de covid-19: \\ indicateurs de l'intensification de l'activite enseignante
}

Danyela Martins Medeiros ${ }^{1}$
Universidade de Brasília

Resumo: Este artigo tem como objetivo de identificar os indicadores de intensificação do trabalho docente da rede pública do Distrito Federal durante a jornada de teletrabalho na pandemia da COVID-19.A partir da análise das respostas obtidas pela aplicação de questionário sobre o trabalho docente no período remoto, aos professores da rede pública, foi possível concluir sobre as consequências da junção entre trabalho remunerado e não remunerado no mesmo tempo e espaço: a sobrecarga de trabalho, intensificação - indicada pelo alongamento de tempo da jornada, pelo acúmulo de atividades e gestão de resultados com a autorresponsabilização sobre os processos de ensino e de aprendizagem influenciadas pelas dinâmicas atuais das políticas educacionais.

Palavras-chave: Jornada de trabalho. Intensificação. Trabalho docente. Pandemia da COVID-19.

\begin{abstract}
This article aims to identify indicators of the intensification of the teaching work in the public network of the Distrito Federal during the teleworking journey in the COVID-19 pandemic. Based on the analysis of the responses acquired by applying a questionnaire about the teaching work in the remote period, for public school teachers, it was possible to conclude on the consequences of joining paid and unpaid work in the same time and space: work overload, intensification - indicated by the lengthening of the workload, by the accumulation of activities and management of results with selfaccountability for the teaching and learning processes influenced by the current dynamics of educational policies.
\end{abstract}

Keywords: Work day. Intensification. Teaching work. COVID-19 pandemic.

Resumée: Cet article veut identifier les indicateurs de l'intensification de l'activité d'enseignement dans le réseau de l'éducation public du Distrito Federal pendant le parcours du télétravail dans la pandémie de COVID-19. Sur la base de l'analyse des réponses obtenues en appliquant un questionnaire sur le travail d'enseignement en période du travail à distance, pour les éleves de l'enseignement public. Il a été possible de conclure sur les conséquences de la jonction du travail rémunéré et du travail non rémunéré dans le même temps et space: supplémente de main- d'oeuvre?, l'intensification du travail - signalée par l'allongement les heures de travail, par le

\footnotetext{
${ }^{1}$ Mestre em educação pela Universidade de Brasília e doutoranda em educação do PPGE/UnB, na Linha Profissão docente, Currículo e Avaliação - PDCA. Professora da Educação Básica da SEEDF.E-mail: danyela.martins@se.df.gov.br. Lattes: http://lattes.cnpq.br/0159031221556347. ORCID: https://orcid.org/o000-0002-5267-2517.
} 
cumul des activités de professeurs et la gestion des résultats avec auto-responsabilité pour les processus d'enseignement et d'apprentissage influencés par la dynamique actuelle des politiques éducatives.

Mots-clés: Journée de travail. Intensification. Pratique pédagogique. Pandémie de COVID-19.

\section{Introdução}

\section{A configuração do tempo de trabalho durante a pandemia}

Este artigo trata das mudanças na jornada de trabalho que passou do regime presencial para o regime de teletrabalho, conforme o Decreto 41.841 que no Distrito Federal direcionou tal mudança aos órgãos, visando a continuidade do funcionamento da administração pública distrital. Para a educação, devido a pandemia da COVID-19, a opção para a continuidade do trabalho pedagógico foi o ensino remoto que, de modo geral, trouxe consequências para as condições de realização do trabalho dos professores, como o aumento da intensificação, a sobrecarga e autorresponsabilização pelos processos de ensino e de aprendizagem. (OLIVEIRA e POCHMANN,2020)

Para esta análise, utilizou-se como instrumento metodológico os dados obtidos em um questionário, com questões abertas e fechadas, com o uso do formulário Google e enviado por WhattsApp, a respeito das condições de trabalho no tipo de jornada imposta após a suspensão das aulas presenciais. O questionário intitulado: O trabalho docente no período remoto, foi realizada no $2^{\circ}$ trimestre da pandemia e obteve 94 respostas de professoras e professores da Educação Básica da Secretaria de Educação do DF. A pandemia ocasionou o impedimento para as aulas presenciais, modificando a relação tempo-espaço de realização do trabalho docente vinculando-o à vida privada das trabalhadoras e trabalhadores professores.

Para melhor entendimento sobre a relação entre tempo e trabalho, o texto traz primeiramente, o conceito de jornada e os aspectos específicos de constituição da carga horária dos professores. Em seguida, a configuração da jornada de trabalho dos professores no Distrito Federal, nosso lócus de pesquisa. Por último, a análise dos dados sobre essa organização de tempo estabelecida pelo teletrabalho - regime concebido como uma excepcionalidade durante a pandemia da COVID-19 e os indicadores da intensificação, sobrecarga e autorresponsabilização pelo trabalhador docente conforte as políticas educacionais atuais que se apresentam como neoliberais. 


\section{Jornada de trabalho dos professores: o trabalho do professor vai além da regência de classe}

Para início do debate sobre a jornada de trabalho, entende-se que ela se expressa primeiramente pelo componente de duração, compreendendo a quantidade de tempo que o trabalho consome da vida das pessoas. Tal duração traz diversas implicações pois afeta a qualidade de vida dos trabalhadores, interferindo na possibilidade de usufruir ou não de mais tempo livre. A jornada é uma questão relevante por uma razão adicional, a saber, a luta pelo tempo livre. Dispor de tempo livre significa alargar o espaço de escolhas e de decisão para realizar atividades edificantes. (DAL ROSSO, 2010, p. 3)

O tempo dedicado ao trabalho remunerado também define a quantidade de tempo durante o qual as pessoas se dedicam a atividades econômicas e estabelece relações diretas entre as condições de saúde, o tipo e o tempo de trabalho executado. Essas razões, explicam porque os estudos de tempo de trabalho que se dedicam à análise da duração se tornaram socialmente tão relevantes (DAL ROSSO, 2006), e ponto central para a discussão das mudanças e afirmação da profissão docente.

No caso do trabalho dos professores, entende-se o tempo em horas semanais ou mensais, em que o profissional da educação fica à disposição do trabalho, entendendo que a atividade docente, além do tempo em sala de aula, está incluso o período dedicado ao planejamento, avaliação e demais atividades relacionadas à docência (JUNIOR, 2000, p.220), ou seja, não se restringe à regência de classe.

Aos dias de hoje, a questão da duração da jornada com a pandemia da COVID-19 transformou-se num problema social e de pesquisa de primeira ordem, por vários motivos cujo o principal é o impacto sobre as condições de realização do trabalho na educação. Há profissionais da educação no setor público e privado que realizam jornadas entre 60 e 70 horas semanais, mesmo antes do período de pandemia. Com isso, avolumam-se os problemas de saúde física e emocional na categoria. Muitos docentes também se submetem a horas de trabalho não remunerado na preparação de aulas, correção de provas, no atendimento a familiares dos alunos e em atividades coletivas nas escolas.

De modo geral, a luta por uma jornada justa para os trabalhadores é uma reivindicação feita pelos movimentos sociais e sindicatos cujo primeiro movimento deu-se com a Constituição Federal de 1988, quando se reduziu a jornada de trabalho de $48 \mathrm{~h}$ para 44 horas semanais dos trabalhadores no país. Quanto ao trabalho docente especificamente, a Lei $n^{\circ}$ 9.394/96, Lei de Diretrizes e Bases da Educação Nacional definiu a jornada como garantia de direitos de horas -aula dos estudantes: “A jornada escolar no ensino fundamental incluirá pelo menos quatro horas de trabalho efetivo em sala de aula [...]” (art. 34 da Lei 9.394/96). As 
questões sobre a duração, composição de jornada de trabalho dos professores e a remuneração são questões heterogêneas nos sistemas de ensino e temas ainda polêmicos no debate nacional quando se trata da tentativa de unificação na carreira magistério.

As discussões em torno da jornada de trabalho não ganharam a centralidade que mereciam e as desigualdades para uma mesma categoria profissional são ainda observadas no país. Em 2013, o Conselho Nacional de Educação publicou recomendações sobre a jornada de trabalho do professor sugerindo ser de "bom tom", embora não obrigatório, que os sistemas de ensino considerem inserir na fração da jornada, as horas destinadas às atividades extraclasse (BRASIL, 2012, p.27). Assim, concebeu-se um espaço no qual toda a equipe de professores pudesse debater e organizar o processo educativo naquela unidade escolar, discutir e estudar temas relevantes para o seu trabalho e para a qualidade do ensino e, que fosse dedicado também à formação continuada, sem mensurar a disponibilidade de tempo para essas atividades.

A questão central é que, externamente, a atividade docente pode dar uma aparência de limite quanto à interação apenas com os estudantes, ou seja, ao período de regência. Porém, como já exposto, a docência não se restringe a sala de aula. É comum aos planos de carreira do magistério uma delimitação de tempo muito maior para a regência e períodos menores para atividades complementares a ela, tais como, o planejamento, a avaliação e a formação continuada docente que por muitas vezes se realizam em períodos não remunerados de trabalho.

A inclusão de horas- atividade ou atividades extraclasse na composição da jornada de trabalho do professor fundamenta-se na necessidade de remunerar o trabalho extraclasse, reconhecendo momentos distintos — de planejamento, execução e avaliação — como inerentes a essa atividade profissional.

Alguns instrumentos legais foram essenciais para o estabelecimento de atividades extraclasses, incluídas na carga horária de trabalho remunerada com destaque à Lei do Piso Salarial Profissional Nacional para os profissionais do magistério público da Educação Básica, Lei 11.738/2008. Esse dispositivo organizou a composição da jornada de trabalho da seguinte forma: "observar-se-á o limite de $2 / 3$ (dois terços) da carga horária para o desempenho das atividades de interação com os educandos" (BRASIL, 17/07/2008). O entendimento é que os outros $1 / 3$ (um terço) da jornada de trabalho docente devem ser exercidos com atividades extraclasse, que tenham contemplem o planejamento, a avaliação e a formação profissional.

As horas-atividade definidas em lei devem incluir trabalho individual e coletivo dos professores sob a perspectiva de que toda aula ministrada pressupõe trabalho prévio de planejamento, preparação de material, assim como de atividade posterior a ela, para 
acompanhamento e avaliação das tarefas dos estudantes, além de formação profissional. O exercício do magistério requer atividades coletivas, para além dessas atividades desenvolvidas individualmente, quer com a integração dos professores entre si para a elaboração da Proposta Pedagógica da escola, reuniões administrativas e pedagógicas para planejamento coletivo; quer com a conexão com a comunidade escolar, por meio de reuniões com pais com orientações sobre o processo de aprendizagem dos estudantes. (LDB, arts. 12, I, 13, I e VI, e 14, I e II).

Ao considerar as horas-atividade na jornada de trabalho remunerado abre-se a possibilidade para o desenvolvimento de programas de educação continuada que articulem o efetivo exercício e as bases teóricas que o sustentam numa perspectiva da epistemologia da práxis, ou seja, de integração entre teoria e prática pedagógica. Os locais para essa formação vão desde ações internas às escolas, desenvolvidas por suas próprias equipes, e externas como formação nas Universidades e demais instituições com esta finalidade.

\section{Composição da jornada de trabalho no distrito federal: espaço-tempo da coordenação pedagógica}

No Distrito Federal, majoritariamente a carga horária de trabalho os professores e professoras, está organizada em 4oh semanais com dedicação exclusiva a regência em uma turma (25h semanais), somado ao período de Coordenação Pedagógica (15h semanais) espaço-tempo para atividades atribuídas à docência como planejamento, avaliação e formação continuada. (DISTRITO FEDERAL, 2016). As horas-atividade, ou atividades extraclasse no DF portanto, é denominada de Coordenação Pedagógica. Essa organização entre regência, de 5horas em um turno e Coordenação Pedagógica de 3 horas no outro, foi um marco para a organização do tempo que desde 1996 com a introdução do Projeto da Escola Candanga ${ }^{2}$. Além de modificar a carga horária docente esse projeto, também aumentou em uma hora o período de aula e para os anos iniciais significou a regência com dedicação exclusiva a uma turma e não em duas turmas, como antes. A jornada de trabalho antes do Projeto Escola Candanga foi orientada por uma carga horária com período de regência de th diárias em cada turno do diurno, portanto, para duas turmas distintas no dia, que poderia dar-se em séries (Anos) diferentes, escolas diferentes e até em outras regiões administrativas do DF. Essa mudança para a jornada ampliada ressignificou o espaço de regência que teve o acréscimo de horas destinadas para planejamento, avaliação e formação na carga horária semanal, possibilitando maior atenção do docente para um grupo menor de estudantes.

\footnotetext{
${ }^{2}$ A Escola Candanga: uma lição de cidadania foi uma proposta político-pedagógica que teve como referência o Plano Quadrienal de Educação do DF (1995-1998) e os eixos definidos pelo Governo Democrático e Popular para a educação - gestão democrática, democratização do acesso escolar e da permanência do aluno na escola e da qualidade na educação (SOUSA, J. V. p. 129-130).
} 
Com essa primeira modificação na jornada, as professoras e professores tiveram as condições de permanecer em apenas uma escola, o que agregou melhoria das condições de trabalho em relação ao deslocamento e atendimento a um número menor de estudantes.

A pesquisa de Medeiros (2017), sobre a Coordenação Pedagógica ilustra bem a questão da busca da melhoria de condições de trabalho das professoras dos anos iniciais no DF, antes da jornada ampliada. O momento da escolha de turmas, realizado no início de cada ano letivo, era marcado pelo grande interesse na escolha de uma mesma série em ambos os turnos pois essa situação facilitaria o planejamento pedagógico que giraria em torno dos mesmos objetivos de ensino. Porém apenas as professoras mais antigas, que obtinham maior pontuação, eram favorecidos por esse mecanismo, ficando os recémempossados com a tarefa de atender séries distintas em ambos os turnos, por vezes em escolas diferentes e até em Coordenações de Ensino diferentes ${ }^{3}$.

Atualmente, a configuração da jornada dos professores estabelecida na Portaria da SEEDF $n^{\circ} 14$ de 11 de janeiro de 2021 , permite três tipos de carga horária docente:

a) 40 horas semanais, em jornada ampliada, sendo $25 \mathrm{~h}$ de regência de classe e 15 horas em coordenação pedagógica;

b) 40 horas semanais, sendo no regime de vinte mais vinte horas, sendo $12 \mathrm{~h}$ em regência de classe e 8h de coordenação pedagógica, em ambos os turnos;

c) 20 horas semanais, diurno ou noturno, sendo 12 horas em regência de classe e 8 horas em coordenação pedagógica (DISTRITO FEDERAL, 2021).

Entendendo que o trabalho na regência está sustentado em um período para planejamento, avaliação e formação que se retroalimenta para atender as situações cotidianas mais atuais, destacamos a essencialidade desse espaço remunerado definido na carga horária dos docentes.

Porém, o espaço-tempo da Coordenação Pedagógica, espaço remunerado de incluído na jornada de trabalho apresenta contradições, desafios e dificuldades, principalmente relacionados à falta ou a precariedade de materiais - como internet, computadores e impressoras - espaços físicos inadequados para o trabalho intelectual, devido ao barulho peculiar das escolas e recursos humanos; assuntos administrativos/burocráticos que, por vezes, sobrepõem os pedagógicos; projetos da SEEDF em desacordo com os da escola; o excesso de eventos e atividades na escola que sobrepõe as questões de aprendizagem e a função de ensinar (MEDEIROS,2017).

${ }^{3}$ Coordenações de Ensino são subdivisões para a gestão das escolas públicas do DF. Ao todo são 14 Coordenações Regionais de Ensino que atendem as 33 Regiões Administrativas do Distrito Federal: Brazlândia, Ceilândia, Gama, Guará, Núcleo Bandeirante, Paranoá, Planaltina, Plano Piloto, Recanto das Emas, São Sebastião, Santa Maria, Samambaia, Sobradinho e Taguatinga. 
De outro modo, a Coordenação Pedagógica inclui o trabalho coletivo, socialização dos saberes profissionais; fortalecimento das relações interpessoais entre todos os servidores da escola; formação continuada na escola, nas coletivas; acesso a cursos com certificação pela EAPE - Centro de Aperfeiçoamentos dos Profissionais da Educação ou outras instituições autorizadas; tempo para planejamentos, pesquisas e avaliações; elaboração de materiais e uso de recursos tecnológicos; espaço para decisões mais democráticas com todos da escola e até por momentos de relaxamento e descontração.

Do mesmo modo, considera-se que a docência está subsumida às relações macroestruturais, políticas, sociais e econômicas capitalistas e que, portanto, estas trazem influências nas condições de trabalho e ensino e das formas de gestão.

A configuração da jornada praticada na rede pública de ensino do DF, ainda é exceção em grande parte do país o que requer uma agenda e espaços que retomem as discussões sobre a igualdade e equilíbrio nas remunerações e jornadas de trabalho nos planos de carreira do magistério público do país.

\section{O teletrabalho durante a pandemia da covid-19: indicadores de intensificação do trabalho docente}

Com a pandemia da COVID-19 no biênio 2020/2021, as aulas presenciais foram suspensas e o trabalho docente foi regulamentado em regime de teletrabalho com atividades remotas ou híbridas.

O teletrabalho, regulamentado desde 2018 no DF, portanto, antes da pandemia, teve como objetivo "proporcionar o aumento de produtividade e qualidade das atividades, economia de tempo e redução de custo com deslocamento de servidores, ampliando ainda as possibilidades de trabalho a servidores com dificuldades de locomoção." (Decreto n 39.368 de 2018) e pode ainda ser visto como uma solução para a mobilidade urbana, e melhor aproveitamento na entrega de resultados. Normalmente, tal modalidade é facultativa e destinada apenas para servidores efetivos que tenham perfil com capacidade de organização e autodisciplina, proativos na resolução de problemas e na orientação para resultados.

Porém, a situação de pandemia lançou os desafios do ensino remoto e do teletrabalho para a Educação Básica, realizada preferencialmente de forma presencial, já que a legislação não permite aulas não-presenciais - com exceção para uma carga-horária de $20 \%$ no ensino médio, chegando até 30\% em cursos noturnos ou $80 \%$ na modalidade para Jovens e Adultos. Com isso, a Portaria Distrital nº 160 de 09 de abril de 2021 regulamentou o teletrabalho para a educação básica com abrangência nas unidades 
escolares da Secretaria de Educação do DF, com atividades a serem desenvolvidas de forma remota ou híbrida, ou seja, ora presencial ora não presencial.

Assim, a jornada de trabalho docente ficou estabelecida temporariamente no ensino remoto com o objetivo de proteger professores, servidores e estudantes do contágio da COVID-19. Nos dados encontrados nas 94 respostas via questionário de nossa pesquisa, as professoras e professores expressaram dificuldades em organizar as 4oh semanais de trabalho e separar os horários somente para a docência e atividades domésticas, somando-se trabalho remunerado e não-remunerado numa mesma jornada. Portanto, as atividades laborais no período da pandemia desenvolveram-se concomitantemente em meio a atividades do âmbito pessoal, como atribuições domésticas e cuidados com a casa, exercícios físicos, educação dos filhos e atividades que deveriam ser atribuídas ao tempo livre, de lazer, descanso e saúde mental.

Destacam-se, principalmente os relatos das professoras que são mães e que assumiram novas atribuições como a de acompanhar as atividades de ensino remoto de seus filhos somado às tarefas domésticas diárias e àquelas destinadas excepcionalmente ao trabalho docente nesse momento na qual somam-se: participar de cursos de formação, planejar atividades para a plataforma, produzir vídeos, planejar atividades escritas impressas para estudantes, contactar pais e responder dúvidas via WhattsApp, participar de reuniões virtuais da escola. Para designar para a rotina de teletrabalho os professores e professoras utilizaram termos como: exaustiva, estressante, cansativa, loucura, demonstrando assim o aumento quantitativo de demandas que geram muitas vezes angústia e incertezas sobre a competência para ensinar nesse modelo on line. Como vemos na fala de uma das respondentes:

P4: Dificuldade em conciliar serviços domésticos, aulas remotas dos filhos, trabalho remoto e trabalho extra em psicoterapia on line [...]

P19: [...] logo no início da pandemia estive totalmente isolada em casa, atendendo às demandas profissionais e domésticas ao mesmo tempo e no mesmo espaço[...]

P33: [...] desdobramento para atender as demandas de profissional, dona de casa e outras necessidades [...]

P39: [...] tenho que cuidar da minha mãe que é idosa, orientar e acompanhe minha filha com as atividades da escola. Tenho também que planejar, postar e acompanhar as atividades na plataforma, além de cuidar das atitudes de casa [...]

A realização dessas duas formas de trabalho - remunerado e não-remunerado requer um dispêndio de energia física e mental aumentada proporcionalmente pelo período de insegurança e ansiedade causado pela pandemia. As consequências dessa associação de trabalhos numa mesma jornada e a falta de delimitação para as horas de 
não-trabalho foram o objetivo desta análise e que já se encontrava como ponto de tensão antes mesmo da pandemia, nas palavras de Dal Rosso, 2010:

$\mathrm{Na}$ sociedade contemporânea, existe uma grande preocupação com a intromissão do labor nas atividades de lazer e de descanso do indivíduo. Como o indivíduo pode ser alcançado em qualquer lugar do mundo pelos meios de comunicação, a convocação para o trabalho a qualquer momento tornou-se uma rotina invasora da privacidade. É a submissão do mundo da vida ao mundo do trabalho. (DAL ROSSO, S. 2010)

Além dessa junção nas formas de trabalho, observa-se no teletrabalho, com o ensino remoto, um alongamento do tempo dispensado ao trabalho remunerado tendo em vista, as novas atribuições exigidas para o momento. Ao serem questionados sobre a rotina de trabalho, identificamos em 47,31 \% das respostas dos professores, expressões relacionadas ao aumento demasiado do tempo destinado ao trabalho remunerado, especificando as atividades realizadas para a docência:

P2: $[\ldots .$.$] ficamos mais de 8 \mathrm{~h}$ conectados [...]

P9: [...] ficar a disposição da escola e pais o dia todo, todos os dias da semana. [ [...

P21: Âs vezes excedo o tempo de trabalho para atender a demanda

P 32: [...] o tempo todo ligada no WhatsApp, sem horário para começar e terminar, até tarde da noite.

P 41: [...] passo dia conversando, tirando dúvida, informando, pedindo ajuda ao grupo das turmas. Olho o tempo todo o grupo dos pais e respondo a todos. Quase sempre ligo para os alunos com laudo [...].

P67: [...] tempo gasto em frente ao computador para planejamento das aulas excede em muito o horário de trabalho [...].

P7 1: [...] não tenho horário mais horário definido de trabalho. Trabalho de manhã, tarde e note e fins de semana. [...]

P76: [...] a única coisa que tenho feito na vida é trabalhar o dia inteiro e as vezes até a noite $[\ldots .$.$] Estou trabalhando umas 5$ vezes mais do que no ensino presencial $[\ldots]$ avalanche de demandas diárias [...].

P81: [...] estamos exaustos, trabalhamos mais de 40 horas semanais [ ...]

As professoras e professores relataram um aumento de tempo de trabalho no período de ensino remoto utilizando expressões que indicam uma tensão entre a jornada remunerada de trabalho, realizado originariamente de forma presencial e a nova jornada imposta pela pandemia, que extrapola ao período remunerado que consta no regime de trabalho de 8 horas diárias e a 40 horas semanais. Os docentes referem-se a um aumento quantitativo de horas de trabalho, com tarefas que se diferenciam das atividades de planejamento, acompanhamento e avaliação dos estudantes no ensino presencial, gerando uma exaustão causada pelo excesso de trabalho e dificuldade em organizar a rotina em horários de trabalho e não-trabalho.

O trabalho docente já apresenta intensificação mesmo antes da pandemia. Existem fatores que colaboram para tal intensificação o primeiro deles é o alongamento das jornadas de trabalho (DAL ROSSO, 2015). Os relatos da vida dos docentes informam sobre práticas de 
jornadas desmesuradamente longas e normas de conduta extremamente rígidas. Com isso, o trabalho docente além da regência, como atividades de preparação das aulas, provas, correções, lançamentos das avaliações é realizado geralmente sem remuneração, ou seja, é muito comum que as professoras e professores do ensino público, levarem atividades, provas para correção ou realizarem planejamentos além do horário previsto na jornada diária remunerada.

Outros indicadores da intensificação do trabalho, o acúmulo de atividades que eram exercidas por mais pessoas, ou seja, a redistribuição de tarefas e cargas de trabalho realizadas por outras pessoas e a gestão de resultados que pode ser entendida como forma de intensificação num sentido mais subjetivo, de cobranças por resultados (DAL ROSSO, 2015). Todos esses indicadores da intensificação do trabalho fazem-se presentes nas respostas dos professores quanto à realização de seu trabalho no ensino remoto.

O indicador de intensificação do trabalho da Gestão de resultados, por exemplo, encontramos nas respostas dos docentes pesquisados, questionamentos que vão além das atribuições da docência e que não estão sob o controle desses profissionais, mas que fazem parte muito comumente do repertório dos docentes: como vamos ensinar a todos sem os meios necessários para o acesso ao ambiente virtual? Como ensinar a todos? Somadas as estas questões estão os gastos inesperados como a necessidade de aquisição de computador e outros dispositivos como fone, mouse, pacotes de internet e no que diz respeito aos estudantes sobre a situação de pobreza, a exclusão dos menos favorecidos economicamente, o acesso à alimentação, a baixa escolarização dos pais que muitas vezes não sabem como auxiliar os filhos, e até o adoecimento e a perda de familiares e amigos.

No contexto político e econômico atual do país as políticas neoliberais expõem uma cruel idealização sobre o desempenho e merecimento, na qual, os professores sentem-se responsabilizados unicamente por não conseguirem atender todos os estudantes de igual forma, e somente os que possuem um mínimo de condições materiais - acesso a internet e computador ou celular - seguirão em seu processo de aprendizagem. Isso integra o cenário de tensões e angústias dos professores ao pensar os resultados das aprendizagens no ensino remoto em tempos de pandemia, deixando uma sensação de frustração e impotência demonstrados nos relatos que se seguem:

P81: Estamos exaustos, trabalhamos mais de 40 horas semanais. E a maior frustração é não poder alcançar todos os alunos (acaba excluindo) e não ser eficaz como o ensino remoto, mesmo nos esforçando ao máximo[...]

P30: [...] tenho buscado estudar bastante sobre o uso delas para colaborar com o trabalho da escola e dos professores. [...] Primeiro que ele é excludente pois nem todos os alunos e professores tem acesso, segundo requer formação e habilidades que nós não temos ou não desenvolvemos ao longo da carreira docente[...] 
P34: Falta de estrutura da SEDF, tanto em relação a saber se os professores têm como manter- se nessa prática, auxílio técnico e principalmente a insegurança emocional. O foco é família e aluno, porém não há preocupação com o profissional que está do outro lado[...]

P46: Não tem sido difícil utilizá-las. Mas tenho dificuldade em edição de vídeos. Também não me sinto confortável em aulas no meet. [...]Percebi poucos aspectos positivos, há apenas a facilidade em explorar os conteúdos disponíveis na internet (como vídeos, leituras, reportagens, etc). A aprendizagem não está sendo efetiva, os professores e os alunos estão desmotivados e cansados. É difícil viver esse momento, em meio a uma Pandemia, com pessoas doentes mental e fisicamente, e ainda precisar exigir tarefas e retorno dos estudantes. Sinto meu trabalho intensificado e sem sentido, pois a função de mediar o conhecimento não está sendo bem-posto em prática. [...]

P54: Tem alunos que não consegui contato, outros não fazem atividade, muitos não têm internet e fazem as vezes. Desproporção, muito tempo gasto para preparar, pouco ou nenhum acesso, resultados. Não consigo conversar com as crianças. Muitas estão se recusando a fazer as atividades porque querem ir à escola. São muitas funções que assumimos e não deveriam ser nós a desempenhar $[\ldots]$

Os professores se autoquestionam sobre suas competências para ensinar diante desse modelo de ensino à distância e indicam uma responsabilização ao pensar como o ensino poderia ter sido melhor oferecido, organizado e planejado para atender a todos os estudantes. A pandemia evidenciou ainda mais as desigualdades educacionais de acesso aos recursos tecnológicos, assim como, as desigualdades sociais. Os filhos da classe trabalhadora em sua maioria mal podem acessar a internet, muitas vezes de celulares com acesso limitado e que não correspondem às expectativas do ensino remoto que estaria pautado em oferecer recursos atraentes para os estudantes do século XXI e principalmente que garantam a interação entre educador e educando, facilitando o acesso à aprendizagem na impossibilidade temporária do ensino presencial. Nas respostas dos docentes foi possível reconhecer uma frustração em não poder realizar o trabalho com a qualidade que faziam antes, além, do evidenciado esgotamento físico e mental resultantes do próprio processo da pandemia concomitante à realização do trabalho remunerado e não-remunerado. Hargreaves (1995) confirma em suas pesquisas sobre a intensificação do trabalho docente, o perverso sentido da autorresponsabilização que se impõe ao professor, mesmo em período anterior ao da pandemia, com a crescente demanda por prestação de contas, mais responsabilidades referentes a aspectos sociais relativos aos discentes e por lidarem com as múltiplas inovações tecnológicas que, entre outras, atestam os problemas de sobrecarga de trabalho. Tal condição afirma o lado perverso da intensificação vem à tona, pois a impossibilidade de responder a todas as questões que emergem causa sofrimento, insatisfação, frustração, cansaço e adoecimento (HARGREAVES, 1995).

Com a mudança na forma no trabalho também, houve a necessidade de formação imediata para acesso aos recursos tecnológicos de apoio ao ensino remoto. Muitos professores se viram inaptos e despreparados para assumir essa nova forma e modalidade de ensino não 
habituais. Em uma sociedade em que a existência de um volume grande de informações ou a centralidade do conhecimento e da valorização social e econômica colocam os professores e professoras diante de tarefas que não podem responder sozinhos por elas. Ao realizar tamanhas tarefas diárias não necessariamente relacionadas ao trabalho pedagógico, o professor perde o sentido do trabalho passando a ser um mero executor de tarefas, aspecto esse que fragiliza a sua afirmação como profissional autônomo e criativo. Outro ponto importante a se considerar é que a intensificação traz com isso a falta de interação entre os pares, afetando a sociabilidade impondo um isolamento que gera um distanciamento às ações coletivas no interior da escola.

Nas pesquisas em países latino-americanos e no Brasil sobre a intensificação do trabalho docente, Oliveira (2006) confirma as situações de intensificação dos professores, que tem como marcas a extensão da jornada dentro do próprio estabelecimento escolar em que o profissional atua. Trata-se de um aumento das horas e carga de trabalho, sem qualquer remuneração adicional com as atividades docentes além da jornada de trabalho remunerada e o profissional é obrigado a levar trabalho para casa. Outra forma de intensificação é que os trabalhadores docentes se sentem forçados a dominar novos saberes e buscar, mesmo com o tempo comprimido, novas competências para o exercício da sua função a fim de responder às exigências dos órgãos do sistema, bem como da comunidade, advindas das reformas educacionais.

Outra condição do trabalho contemporâneo é a busca para responder às demandas sociais como as desigualdades sociais e falta de acesso aos recursos para o ensino "on line", como foi a necessidade prioritária na pandemia. Segundo Nóvoa, (2013), é preciso ter consciência que os problemas da educação não serão resolvidos no interior das escolas.

Dessa forma, é necessário um trabalho político, com maior presença dos professores da escola pública no debate, uma consciência clara da importância da educação para a sociedade do século XXI e principalmente um projeto de educação para a nação que considere o ajustamento das jornadas de trabalho no magistério.

\section{Conclusões}

Ao destacar a jornada de trabalho docente na atualidade, abre-se uma discussão mais ampla sobre as condições do trabalho do professor em relação às horas remuneradas para este trabalho, que devem contemplar não só o período de regência, mas considerar o direito do professor ao período dedicado ao planejamento e a formação do profissional, garantidos em lei.

O alongamento da jornada e intromissão do trabalho remunerado no espaço privado de vida dos professores afetam diretamente as condições de trabalho mesmo antes da pandemia, como uma situação comum aos docentes. Os indicadores da intensificação do trabalho - alongamento do tempo, acúmulo de atividades e a gestão de resultados - a 
sobrecarga e a autorresponsabilização são naturalizados pelas dinâmicas do trabalho remoto asseguradas pelas políticas educacionais neoliberais que orientam a educação nesse momento.

Há necessidade de uma definição de uma jornada remunerada compatível com o trabalho, ou seja, com tempo suficiente para atender as especificidades do trabalho docente e além disso, que permita o tempo livre para o descanso e lazer ao trabalhador professor. Tal jornada determinada, integrada a outros aspectos como - salário, carreira, formas de ingresso, formação permanente, condições adequadas de realização do trabalho, reconhecimento social, autorrealização e dignidade profissional coadunam com a tão desejada valorização dos professores e professoras.

\section{Referências}

BRASIL. Conselho Nacional de Educação. Câmara de Educação Básica. Estudo sobre a lei do Piso Salarial. Disponível em:

http://portal.mec.gov.br/index.php?toption=com_docman\&view=download\&alias=10241estudo-sobre-lei-piso-salarial\&Itemid=30192. Acesso em 15 abr.2016.

BRASIL. Constituição (1988). Constituição da República Federativa do Brasil. Brasília, DF: Senado Federal: Centro Gráfico, 1988.

BRASIL. Lei $n^{\circ} 11.738$, de 17 de julho de 2008. Regulamenta a alínea "e" do inciso III do caput do art. 60 do Ato das Disposições Constitucionais Transitórias, para instituir o piso salarial profissional nacional para os profissionais do magistério público da educação básica. Diário Oficial da União de 17 de julho de 2008. Disponível em: http://www.planalto.gov.br/ccivil_03/_ato2007-2010/2008/lei/l11738.htm. Acesso em: 8 mar. 2016.

BRASIL. Lei no 9.394, de 20 de dezembro de 1996. Diário Oficial da União de 23.12.1996. Estabelece as diretrizes e bases da educação nacional. Disponível em: http://www.planalto.gov.br/ccivil_03/Leis/L9394.htm. Acesso em: 6 fev. 2016.

BRASIL. Parecer do Conselho Nacional de Educação no 18/2010. Diário Oficial da União de $01^{\circ}$ de agosto de 2013, seção 1, página 19. Brasília, 2013.

CURADO SILVA, Kátia, A. P. C. Epistemologia da práxis na formação de professores: perspectiva crítico-emancipadora. Campinas, SP: Mercado de Letras, 2018.

DAL ROSSO, S. Jornada de trabalho. In:OLIVEIRA, D.A.; DUARTE, A.M.C.; VIEIRA, L.M.F. DICIONÁRIO: trabalho, profissão e condição docente. Belo Horizonte: UFMG/Faculdade de Educação, 2010. CDROM.

DAL ROSSO, S. Mais trabalho! A intensificação do labor na sociedade contemporânea. São Paulo: Boitempo, 2008.

DiSTRITO FEDERAL. Cadernos da Escola Candanga, Diretrizes Operacionais da Coordenação Pedagógica. Série Diretrizes Operacionais, no 01. Secretaria de Educação do Distrito Federal. Governo do Distrito Federal, Brasília, 1996. 
DISTRITO FEDERAL. Decreto $n^{\circ} 39.368$ de 2018. Institui e regulamenta o teletrabalho e dá outras providências. Diário Oficial do Distrito Federal n ${ }^{\circ} 191$, seção 1,2 e 3 de 05 de outubro de 2018.

DISTRITO FEDERAL. Portaria $n^{0} 14$ de 11 de janeiro de 2021. Diário Oficial do Distrito Federal $n^{\circ} 08$ de 13 de janeiro de 2021.

DISTRITO FEDERAL. Portaria $n^{\circ} 27$ de 18 de fevereiro de 2016. Diário Oficial do Distrito Federal n ${ }^{\circ} 33$ de 19 de fevereiro de 2016.

DUARTE, A.M.C. Intensificação do trabalho docente. In:OLIVEIRA, D.A.; DUARTE, A.M.C.; VIEIRA, L.M.F. DICIONÁRIO: trabalho, profissão e condição docente. Belo Horizonte: UFMG/Faculdade de Educação, 2010. CDROM

HARGREAVES, A. Profesorado, cultura y postmodernidad: cambian los tiempos, cambia el professorado. Madrid: Morata, 1995.

JUNIOR, Adhemar F. Dutra et. al. Plano de carreira e remuneração do magistério público: LDB, Fundef, Diretrizes Nacionais e Nova concepção de carreira. Brasília, MEC, FUNDESCOLA, 234 p. MEC. INEP, 2000.

OLIVEIRA, D. A. O trabalho docente na América Latina: identidade e profissionalização. Retratos da escola, Brasília. v. 2, n. 2/3, p. 29-40, jan. dez. 2008. DOI:

https://doi.org/10.1590/s0102-46982006000200011.

OLIVEIRA, D. A. Regulação educativa na América Latina: repercussões sobre a identidade dos trabalhadores docentes. Educação em Revista, Belo Horizonte, v. 44, p. 209-228, dez. 2006

MEDEIROS, Danyela Martins. Coordenação pedagógica: elementos instituintes e instituídos na construção da profissionalidade docente no DF. 2017. 169 páginas. Dissertação (Mestrado em Educação). Data da defesa: 12 de dezembro de 2017.Universidade de Brasília, Brasília, 2017.

NÓVOA, António. Nada substitui um bom professor: propostas para uma revolução no campo da formação de professores. In: GATTI, B. A, et al. Por uma política Nacional de Formação de Professores. $1^{\text {a }}$ edição. Editora Unesp, 2013.

OLIVEIRA, Dalila; POCHMANN, Márcio (Org.). A Devastação do trabalho: a classe do labor na crise da pandemia.1. ed. - Gráfica e Editora Positiva: CNTE - Confederação Nacional dos Trabalhadores em Educação e Grupo de Estudos sobre Política Educacional e Trabalho Docente, Brasília, 2020. 